\title{
Numerical prediction for a heat exchanger performance by employing various orientations of longitudinal fins
}

\author{
Hiyam Abed Kareem $^{\dagger}$,Khudheyer S. Mushatet ${ }^{\ddagger}$, Mohsen H. Fagr ${ }^{\dagger}$ \\ ${ }^{\dagger}$ First author's Mechanical Engineering, Collage of Engineering, Thi -Qar University, Iraq, hiyamabid@ gmail.com \\ †'Second author’s Mechanical Engineering, Collage of Engineering, Thi -Qar University, Iraq, khudheyersalim@ gmail.com \\ ${ }^{\dagger}$ Third author's Mechanical Engineering, Collage of Engineering, Thi -Qar University, Iraq, mohafagr@yahoo.com
}

\begin{abstract}
:
This paper studies numerically the impact of installing longitudinal fins on the performance of a DPHE. Different heights were considered for these fins and three different profiles; rectangular, triangular, and semi-circular were investigated. Fins were fixed on the internal surface of the annulus side. The numerical investigation was carried out for counter flow. The study is performed in two cases. The first one was of a constant hot water mass flow rate $\left(\mathrm{m}_{\mathrm{h}}\right)$ at $(0.3) \mathrm{kg} / \mathrm{s}$ and varying values of cold water mass flow rate $\left(\mathrm{m}_{\mathrm{c}}\right)$ which was from 0.2 to $1 \mathrm{~kg} / \mathrm{s}$. The second case was of a constant cold water mass flow rate $\left(\mathrm{m}_{\mathrm{c}}\right)$ at $(0.3) \mathrm{kg} / \mathrm{s}$ and changing hot water mass flow rate $\left(\mathrm{m}_{\mathrm{h}}\right)$ which was from 0.2 to $1 \mathrm{~kg} / \mathrm{s}$. Inlet temperature of hot water was $353 \mathrm{k}$ and for cold water was $298 \mathrm{k}$. The results showed that using longitudinal fins enhances the (DPHE) thermal performance. Also, semi-circular profile gave more enhancement in the rate of heat transfer compared to other studied profiles.
\end{abstract}

keywords: CFD, longitudinal fins, Heat transfer

\section{Introduction}

Various techniques are used to improve heat transfer in heat exchangers, both of which can be categorized as passive and active techniques. Passive techniques do not need any external control, for example extended surfaces, coating, and surface roughness. Active techniques need an external power for example injection, induced vibrations, and jet impingement and suction of fluids [1]. For a long time, fins were used to improve heat transfer rate from surfaces to the surrounding as they provide an inexpensive and effective means to enhance heat transfer rate. It used in a lot of applications including nuclear reactors, petroleum and electronic industries, power plants, and chemical processes [2]. Many researchers studied the effect of installing fins on the double pipe heat exchanger thermal performance. Sreedhar and Varghese [3] the results found that the external fins is the ideal design for cooling the hot fluid in the inner pipe of DPHE. Reddy and Rajagopal [4] The results observed that the pressure drop is increase with the increasing of the mass flow rate and fins number. Nada and Said [5]. the results indicated that the heat transfer and effective thermal conductivity increase with the increasing of fins number, fins width, and Rayleigh number. Mathanraj et al. [6] it was found that the effectiveness and heat transfer increases with the increasing of mass flow rate. It is also observed that the overall heat transfer coefficient increases too and log mean temperature difference decreases. Majidi et al. [7] the obtained results showed that the overall heat transfer coefficient increases by increasing the Reynolds number. Ramu et al. [8]. results indicated that the heat transfer rate and the heat transfer coefficient increase as the mass flow rate increases. Hameed and Essa [9] results showed that the temperature difference is decrease as the Reynolds number increase. Karamallah and Hoshi [10] the results showed that the friction factor is increase as the pitch decreases.
As seen through the previous literature review, heat exchangers still need to more efforts to enhance their heat transfer more and more. In the present research, longitudinal fins of different cross sections were studied to show their effects on the duty of the DPHE.

\section{Physical model}

The physical model of DPHE was built using ANSYS 17.2. The inner diameter (di) of the inner pipe is $20 \mathrm{~mm}$, and the inner diameter (Di) of the outer pipe is $44 \mathrm{~mm}$, the thickness of both pipes is $2 \mathrm{~mm}$, with exchanger length (L) of $1000 \mathrm{~mm}$. For counter flow arrangement hot water flows in the tube side, cold water flows in the annulus side. The material of pipes and fins is copper because of it is highly thermal conductivity. Four cases of the internal surface of the annulus side were investigated: No fins, longitudinal rectangular finned surface, longitudinal triangular finned surface, longitudinal semi-circular finned surface. The schematic representation of the four cases of the internal surface of the annulus side shown in Fig.1. In both longitudinal rectangular finned surface and longitudinal triangular finned surface, Four fins are fixed circumferentially on the internal surface of the annulus side, different fin height (Hf) of $2.5 \mathrm{~mm}, 5 \mathrm{~mm}$, and $7.5 \mathrm{~mm}$ were used, while fin base width (tf) kept constant at $1 \mathrm{~mm}$. In longitudinal semi-circular finned surface, different fins radius (r) of $2.5 \mathrm{~mm}, 5 \mathrm{~mm}$, and $7.5 \mathrm{~mm}$ were used and Four fins are placed around the thickness of the outer pipe. 


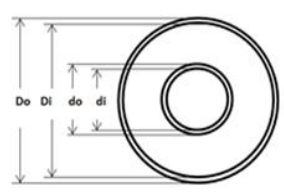

(a)

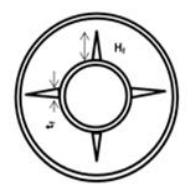

(c)

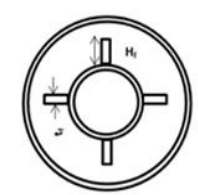

(b)

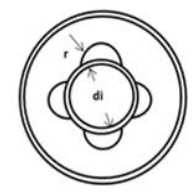

(d)
Fig.1. Schematic representation of the four conditions of the annulus (a) No. Fins, (b) Rectangular finned annulus, (c) Triangular finned annulus, (d) Semi-circular finned annulus.

\section{Mathematical model}

The governing equation of continuity, momentum, and energy for, three dimensional, incompressible fluid and steady state flow are summarized as [11]:

The model of k-epsilon is used to treat the influence of turbulence on the flow. Transport equations in the standard k- $\varepsilon$ model are written as follows [12]:

Turbulence kinetic energy (k) equation:

$$
\frac{\partial}{\partial x_{i}}\left(\rho k u_{i}\right)=\frac{\partial}{\partial x_{i}}\left(\left(\mu+\frac{\mu_{t}}{\sigma_{k}}\right) \frac{\partial k}{\partial x_{j}}\right)+G_{k}+G_{b}-\rho \varepsilon-Y_{M}+S_{k}
$$

Turbulent energy dissipation $(\varepsilon)$ equation:

$$
\frac{\partial}{\partial x_{i}}\left(\rho \varepsilon u_{i}\right)=\frac{\partial}{\partial x_{i}}\left(\left(\mu+\frac{\mu_{t}}{\sigma_{\varepsilon}}\right) \frac{\partial \varepsilon}{\partial x_{j}}\right)+C_{1 \varepsilon} \frac{\varepsilon}{k}\left(G_{k}+C_{3 \varepsilon} G_{b}\right)-C_{2 \varepsilon} \rho \frac{\varepsilon^{2}}{k}+S_{\varepsilon}
$$

The turbulent viscosity is:

$$
\begin{gathered}
\frac{\partial u_{i}}{\partial x_{i}}=0 \\
\frac{\partial u_{i} u_{j}}{\partial x_{i}}=-\frac{\partial \mathrm{P}}{\rho \partial x_{i}}+\frac{\partial}{\partial x_{j}}\left(\left(\mu+\mu_{t}\right)\left(\frac{\partial u_{i}}{\partial x_{j}}+\frac{\partial u_{j}}{\partial x_{i}}\right)\right) \\
\frac{\partial u_{i} T}{\partial x_{i}}=\rho \frac{\partial}{\partial x_{i}}\left(\left(\frac{\mu}{p r}+\frac{\mu_{t}}{p r_{t}}\right) \frac{\partial T}{\partial x_{i}}\right) \\
\mu_{t}=\rho c_{\mu} \frac{k^{2}}{\varepsilon}
\end{gathered}
$$

Where $\mathrm{C}_{\mu}=0.09, \mathrm{C}_{1 \varepsilon}=1.44, \mathrm{C}_{2 \varepsilon}=1.92, \sigma_{\mathrm{k}}=1, \sigma_{\varepsilon}=1.3$

\subsection{Boundary conditions}

The studied model was subjected to the boundary conditions as bellow:

1. At the inlets: mass-inlet is set as a boundary condition of inlets in two cases:

(a) $\mathrm{m}_{\mathrm{c}}$ is selected as $(0.2,0.4,0.6,0.8,1) \mathrm{kg} / \mathrm{s}$ and $\mathrm{m}_{\mathrm{h}}$ kept constant at $(0.3 \mathrm{~kg} / \mathrm{s})$.

(b) $\mathrm{m}_{\mathrm{h}}$ is selected as $(0.2,0.4,0.6,0.8,1) \mathrm{kg} / \mathrm{s}$ and $\mathrm{m}_{\mathrm{c}}$ kept constant at $(0.3 \mathrm{~kg} / \mathrm{s})$.

And $\mathrm{T}_{\mathrm{hi}}=353 \mathrm{k}, \mathrm{T}_{\mathrm{ci}}=298 \mathrm{k}$.

2. At pipe walls: no-slip boundary condition is imposed.

3. At the outer walls of heat exchanger: boundary condition of zero heat is considered.

4. At the interface between the fins and fluid through annulus: have coupling heat transfer boundary condition.

5. At the outlets: Relative gage pressure is assumed to be zero.

\section{Data reduction}

To investigate the characteristic of finned and unfinned double pipe heat exchanger some parameters are need to be determined [13-17].

Reynolds number and velocities of the tube and annulus side are defined as follows: 


$$
\begin{aligned}
& R e_{i}=\frac{\rho D_{h, i} V_{i}}{\mu} \\
& R e_{o}=\frac{\rho D_{h, o} V_{o}}{\mu} \\
& V_{i}=\frac{m_{h}}{\rho A_{c, i}} \\
& V_{o}=\frac{m_{c}}{\rho A_{c, o}} \\
& \text { Where } D_{h, i}=\frac{4 A_{C, i}}{P_{w, i}} \text { and } D_{h, o}=\frac{4 A_{C, o}}{P_{w, o}}
\end{aligned}
$$

the heat transfer coefficient of tube and annulus side $h_{i}, h_{o}$ are calculated from the following equations:

$$
\begin{gathered}
h_{i}=\frac{m_{h} c p_{h}\left(T_{h i}-T_{h o}\right)}{A_{s, i}\left(T_{s, i}-T_{m, i}\right)} \\
h_{0}=\frac{m_{c} c p_{c}\left(T_{c o}-T_{c i}\right)}{A_{s, o}\left(T_{s, o}-T_{m, o}\right)}
\end{gathered}
$$

Where $A_{i, i}=\pi d_{i} L$ and $A_{i, o}=\pi d_{o} L$

If there are fins placed on the pipe, the total surface area can be calculated as:

$$
A_{t}=A_{u f}+A_{f}
$$

The tube and annulus sides average Nusselt number is determined as follow:

$$
\begin{aligned}
& N u_{i}=\frac{h_{i} D_{h, i}}{k_{f}} \\
& N u_{o}=\frac{h_{o} D_{h, o}}{k_{f}}
\end{aligned}
$$

Overall heat transfer coefficient is determined as follow:

$$
U=\frac{Q_{\text {avg }}}{A_{s, o} L M T D}
$$

Where:

$$
Q_{\text {avg }}=\frac{Q_{h}+Q_{c}}{2}
$$

And logarithmic mean temperature difference

$$
L M T D=\frac{\Delta T_{1}-\Delta T_{2}}{\ln \left(\frac{\Delta T_{1}}{\Delta T_{2}}\right)}
$$

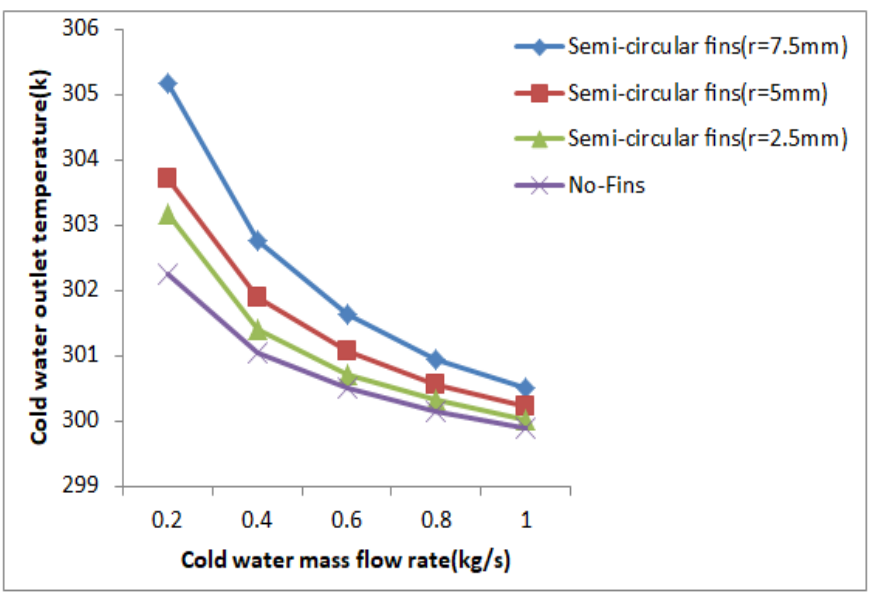

\section{Numerical analysis}

To estimate the fluid flow characteristics and heat transfer, there is a requirement to solve the equations of mathematical model by transforming them to algebraic equations using finite volume method. The continuity, momentum, and energy equations are integrated and converted to algebraic equations. The SIMPLE algorithm used to resolve the pressure velocity coupling. To make sure that the solution has high accuracy, grid refinement was performed to check the influence of mesh size on the solution. Mesh refinement have been tested for all studied cases. Table.1. shows the specified number of elements for the studied cases.

Table 1 Specified number of elements.

\begin{tabular}{|l|c|}
\hline \multicolumn{1}{|c|}{ case } & $\begin{array}{c}\text { Number of } \\
\text { element }\end{array}$ \\
\hline Unfinned double pipe heat exchanger & 911574 \\
\hline $\begin{array}{l}\text { Double pipe heat exchanger with rectangular } \\
\text { fins }\left(\mathrm{H}_{\mathrm{f}}=7.5 \mathrm{~mm}\right)\end{array}$ & 1137014 \\
\hline $\begin{array}{l}\text { Double pipe heat exchanger with triangular } \\
\text { fins }\left(\mathrm{H}_{\mathrm{f}}=7.5 \mathrm{~mm}\right)\end{array}$ & 1113778 \\
\hline $\begin{array}{l}\text { Double pipe heat exchanger with semi-circular } \\
\text { fins }\left(\mathrm{r}_{\mathrm{f}}=7.5 \mathrm{~mm}\right)\end{array}$ & 1176264 \\
\hline
\end{tabular}

\section{Validation}

In this study to check the validity, a validation is done by solving the model that presented by Kumar et al. [1] and compared the numerical results with the experimental results of [1]. Fig. 2. Indicates the relation between the cold water outlet temperature and mass flow rate of hot water for unfinned DPHE. It is observed that the average error between the results is about $0.215 \%$. 


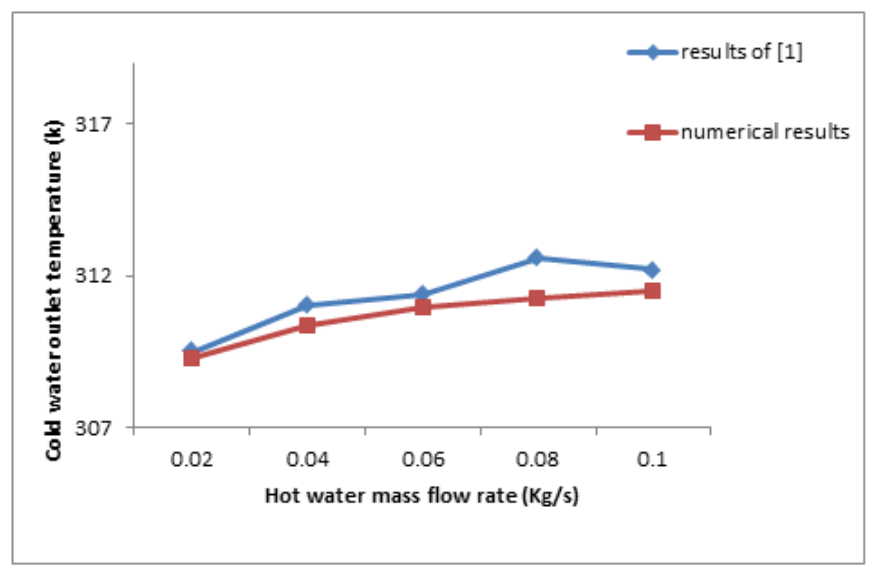

Fig. 2. Validation of the results of [1] with numerical results.

\section{Results and discussions}

The numerical results that obtained from this study including the effect of a different configuration of fins on the cold water, hot and cold water outlet temperature difference, the rate of average heat transfer, heat transfer rate of cold water, overall heat transfer coefficient, pressure drop, cold water heat transfer area over the annulus side pressure drop and Nusselt number in the annulus side over the annulus side pressure drop are listed as follow:

Fig.3. shows the relation between cold water outlet temperature and cold water mass flow rate while hot water mass flow rate kept constant for semi-circular finned DPHE. This figure indicates that the cold water outlet temperature increases with the increase in semi semi-circular fin radius, and fins with a radius of $7.5 \mathrm{~mm}$ shows better results, this is because when the semicircular fin radius increases the heat transfer area is also increase.

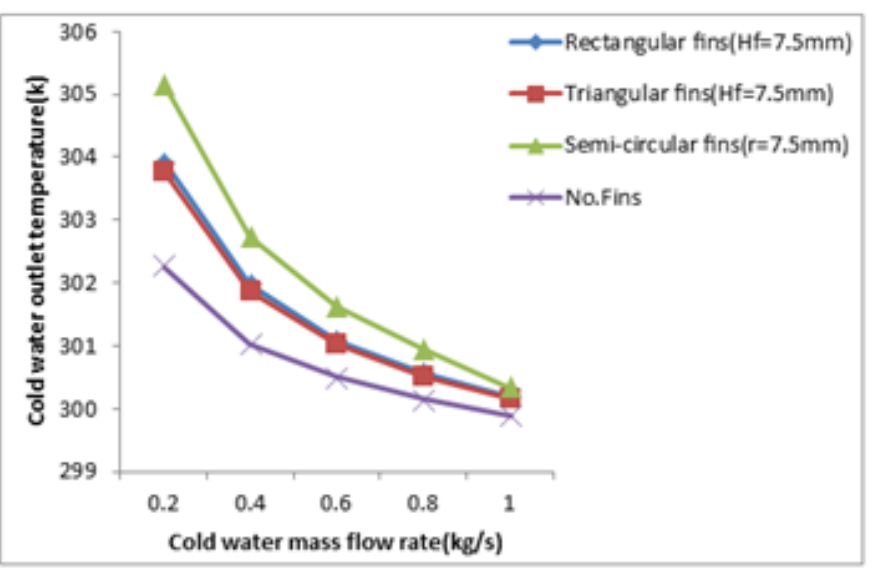

Fig. 3. Changes of cold water outlet temperature versus mass flow rate of cold water for different configurations of fins.

Fig.4. indicates the relation between the cold water outlet temperature and mass flow rate of cold water. This figure shows that cold water outlet temperature decreases when cold water mass flow rate increases for all cases. Because at a constant hot water mass flow rate the heat energy that dissipated from inner pipe kept constant, and when cold water mass flow rate increases the heat transfer rate increases too, because the turbulence is increased too. Also, fig.4. shows that the outlet temperature of cold water for the FDPHE finned pipes is higher compared to unfinned ones, and semi-circular FDPHE shows better results compared to other fins configurations, this is due to it is larger surface area. Semi-circular fins show average improvement in cold water outlet temperature by $0.21 \%$ and $0.24 \%$ over the rectangular and triangular fins.

Fig. 4. variation between the cold water outlet temperature with cold water mass flow rate for different configurations of fins.

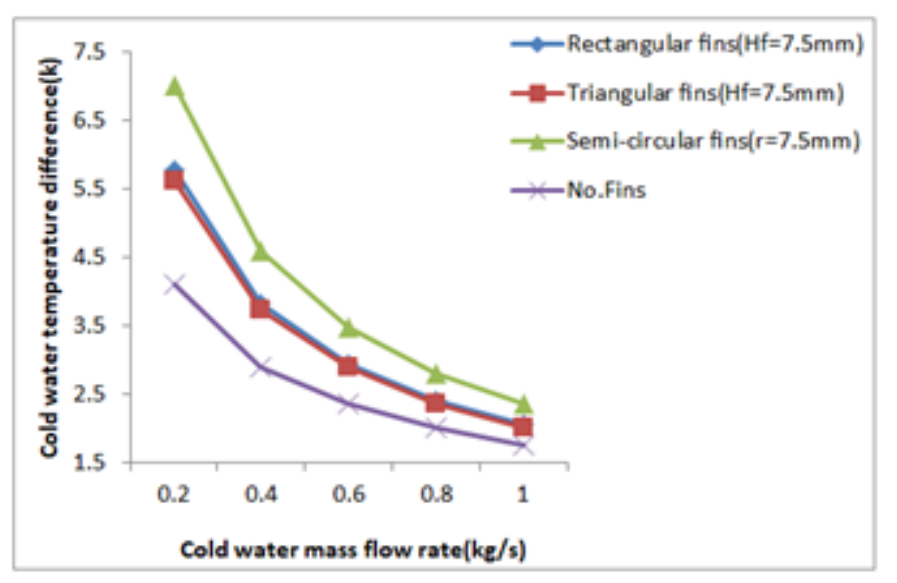

Fig.5. explains the relation between cold water outlet temperature and hot water mass flow rate. The figure observed that cold water outlet temperature for the FDPHE is higher compared to unfinned DPHE and increases when mass flow rates increases for all cases. Because the increases in the hot water mass flow rate will increase the heat energy that dissipated from the inner pipe. Also, the semi-circular FDPHE has an average improvement in cold water outlet temperature by $0.48 \%$ and $0.53 \%$ over the rectangular and triangular FDPHE. 
Fig. 5. Changes of cold water outlet temperature and hot water mass flow rate for different configurations of fins.

From fig. 4. and fig .5. It can be seen that to have a better performance of fins cold water mass flow rate must be low and hot water mass flow rate should be high.

Fig. 6. indicates the relation of the temperature difference of cold water and cold water mass flow rate. This figure shows that cold

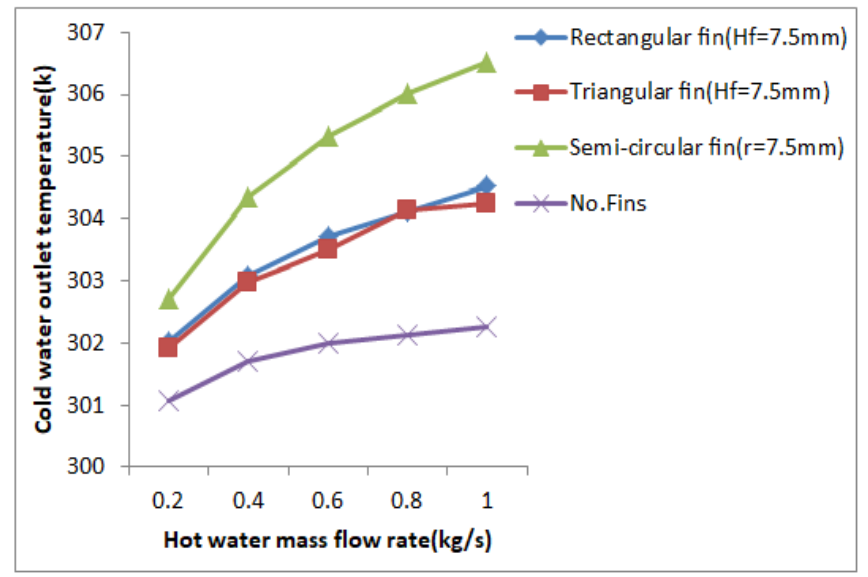

water temperature difference, increases when fins are used, and also this figure shows that the temperature difference decreases when cold water mass flow rate increase. Because the annulus side heat transfer area increases when the surface area increases. The difference in temperature of cold water decreases when mass flow rate increase. Also, this figure shows that semi-circular FDPHE has better results compared to other fin profiles, due to it is larger surface area.
Fig. 6. Variation between the temperature difference of cold water and cold water mass flow rate for different configurations of fins.

Fig. 7. presents the relation of the hot water temperature difference and cold water mass flow rate. This figure that the difference in temperature increase when cold water mass flow rate increase, rate due to an increase in velocity. The FDPHE has a higher difference in temperature compared to the unfinned DPHE and semi-circular FDPHE shows better results compared to rectangular and triangular FDPHE because when surface area increases heat transfer area is also increased.

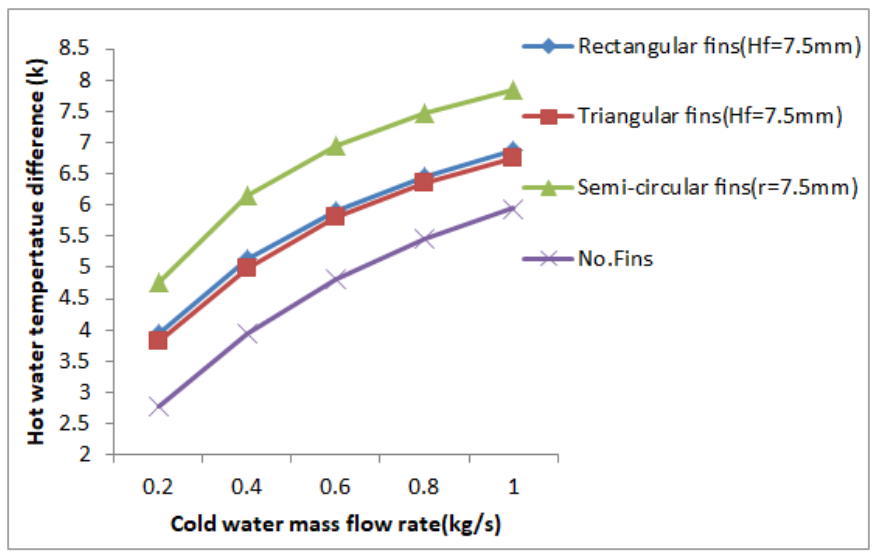

Fig. 7. Variation between the temperature difference of hot water and cold water mass flow rate different configurations of fins.

Fig. 8. shows the relation between the rate of average heat transfer and cold water mass flow rate. This figure indicates that when cold water mass flow rate increase the rate of average heat transfer is also increase for all cases due to increase in the amount of heat transfer, average heat transfer rate in FDPHE is more than that of unfinned DPHE, because the surface area is increased. And also indicates that the average heat transfer for the semi-circular FDPHE is more than that for rectangular and triangular FDPHE, due to their larger heat transfer area. 


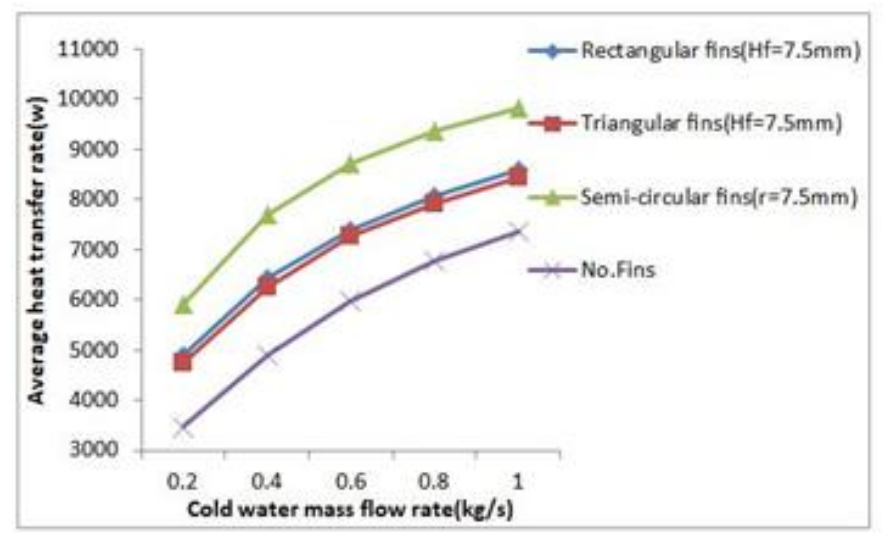

Fig. 8. Changes of the rate of average heat transfer rate versus mass flow rate of cold water different configurations of fins for different configurations of fins.

Fig.9. explains the relation of the rate of heat transfer of cold water and cold water mass flow rate. This figure indicates that the rate of heat transfer of cold water increases when cold water mass flow rate increase, because the increases in cold water mass flow rate increase the heat transfer amount too, for all cases. Also, this figure shows that cold water heat transfer for the FDPHE is much better than the unfinned DPHE, semi-circular FDPHE shows the best improvement in the heat transfer because the area of heat transfer in this case is larger than other fins configuration.

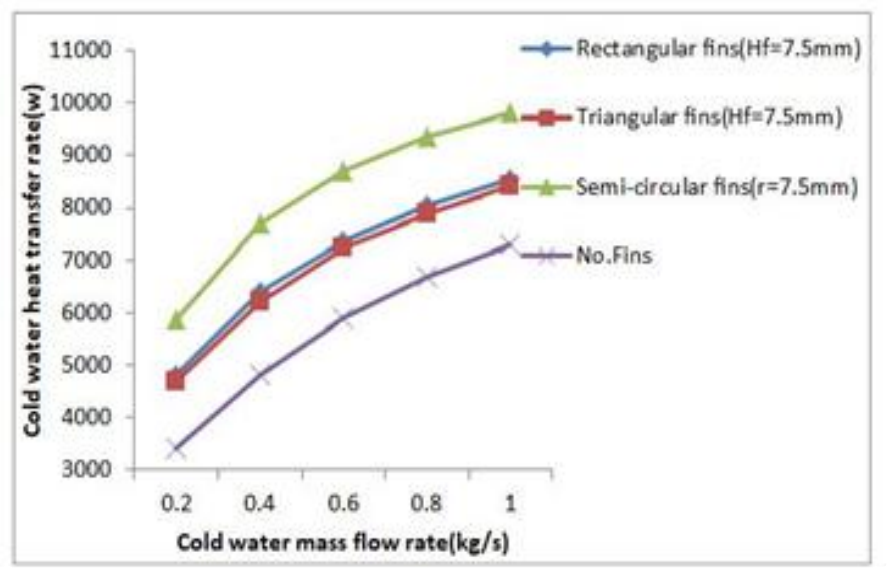

Fig. 9. Changes of the cold water heat transfer versus cold water mass flow rate for different configurations of fins.

Fig.10. explains the relation between the coefficient of overall heat transfer and mass flow rate of cold water, this figure indicates that when cold water mass flow rate increases the overall heat transfer coefficient increase too, because a large amount of heat is transferred. For the FDPHE is much higher than for unfinned pipe, the overall heat transfer coefficient was highest in the semi-circular FDPHE, due to it is large heat transfer area.

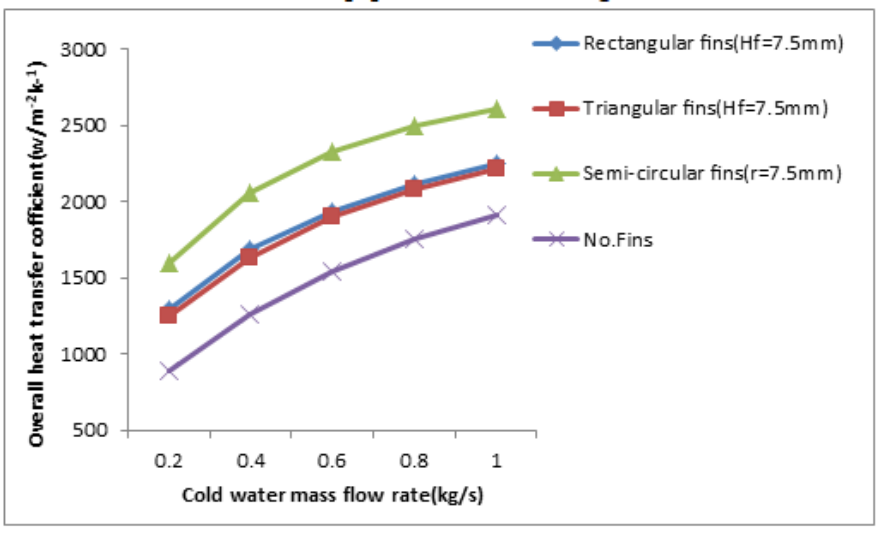

Fig. 10. Changes of the coefficient of overall heat transfer versus mass flow rate of cold water for different configurations of fins.

Fig.11. presents the relation of annulus side pressure drop with cold water mass flow rate, this figure indicates that the pressure drop is higher in the FDPHE, and increases when cold water cold water increase, also for FDPHE minimum pressure drop is in the case of triangular fin shape and highest pressure drop in semicircular fin shape. This is because the area of the cross-sectional of the annulus side is decreases when the surface area of fins increases.

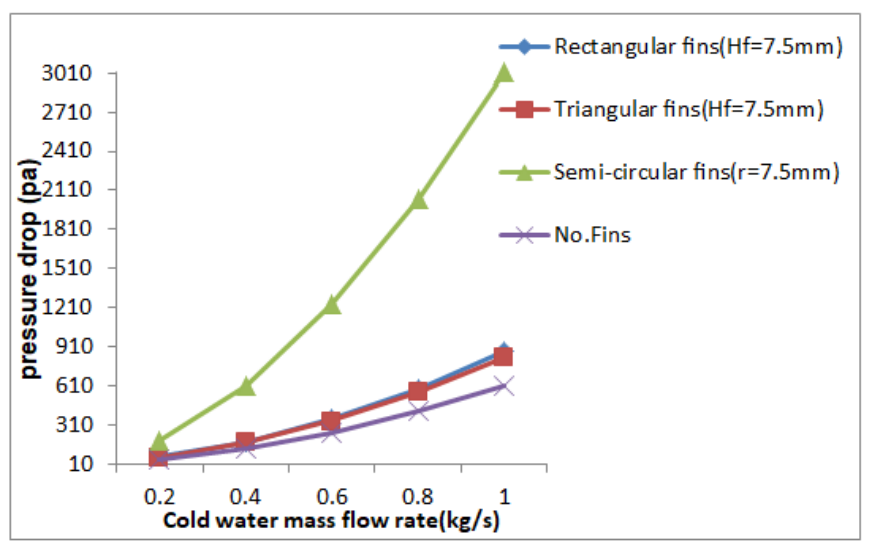

Fig. 11. Variation between the annulus side pressure drop and cold water mass flow for different configurations of fins.

Fig. 12. represents the relation between the ratio of rate of heat transfer for cold water and the annulus side pressure drop with mass flow rate of cold water. This figure shows that $\left(\mathrm{Q}_{\mathrm{c}} / \Delta \mathrm{p}\right)$ is higher for unfinned DPHE because the heat transfer for cold water and pressure drop are lesser than that for FDPHE, this is because the area of heat transfer is smaller compare to the finned ones. 


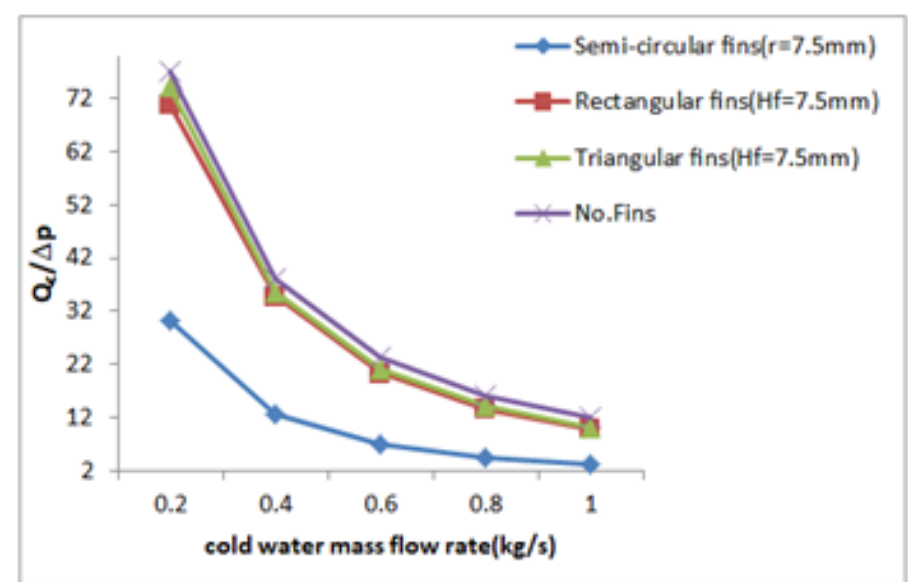

Fig. 12. Changes of cold water heat transfer rate water and annulus side pressure drop ratio versus cold water mass flow rate for different configurations of fins.

Fig. 13. explains the relation of the ratio of Nusselt number in the annulus side and annulus side pressure drop with cold water mass flow rate, this figure shows that for FDPHE this ratio is higher than the unfinned DPHE, this is because the Nusselt number of the unfinned DPHE is more than FDPHE due to it is high hydraulic diameter, and low pressure drop due to it is small heat transfer area.

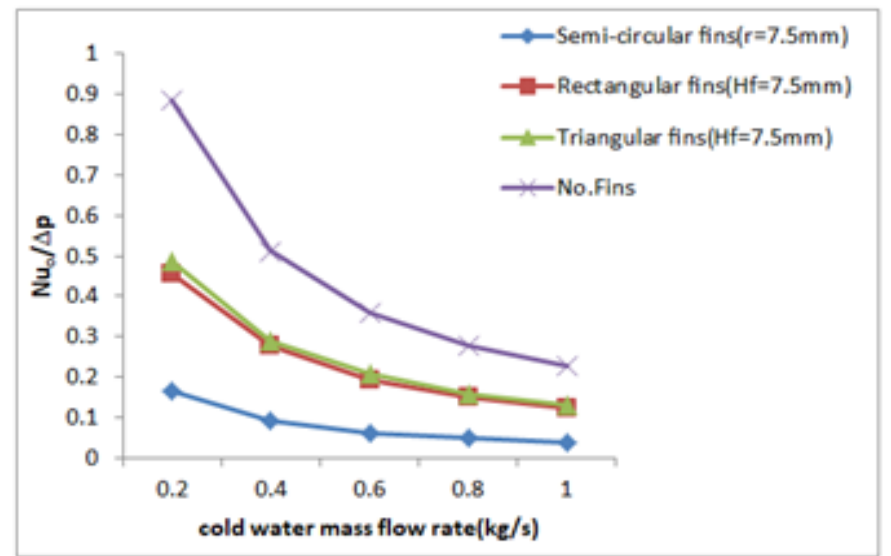

Fig. 13. Changes of the Nusselt number in the annulus side and annulus side pressure drop ratio versus cold water mass flow rate for different configurations of fins.

Fig. 14. illustrations the temperature contours for unfinned (DPHE) and (FDPHE), at the hot water inlet and cold water outlet. It can be seen that the temperature gradients near the tube wall and fins are quite high, due to enhanced heat transfer. Also, this figure shows that the semi-circular FDPHE shows better temperature distribution compared to heat exchanger with rectangular and triangular fins.

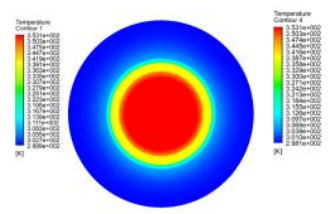

(a)

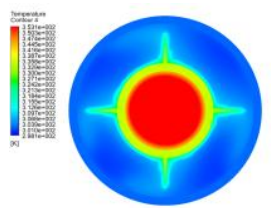

(c)

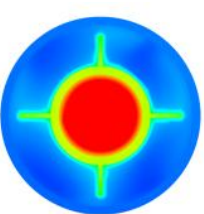

(b)
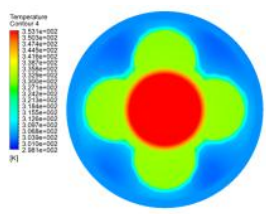

(d)
Fig.14. temperature contour at hot water inlet and cold water outlet (a) No. Fins (b) Rectangular (c) Triangular (d) Semicircular finned annulus. at $\mathrm{m}_{\mathrm{h}}=0.3$ and $\mathrm{m}_{\mathrm{c}}=0.2 \mathrm{~kg} / \mathrm{s}$

Fig. 15. Shows the temperature contours in the cross section for unfinned (DPHE) and (FDPHE) with rectangular, triangular, semi-circular and annular fins at axial location of $0,0.2,0.4,0.6$ , 0.8 and $1 \mathrm{~m}$. From the figures, it can be seen that at the entrance region the inlet temperature of the hot water is maximum and due to the transfer of heat with cold water through wall and fins its gradually decreased by moving along the pipe towards the outlet reaching its lower value.

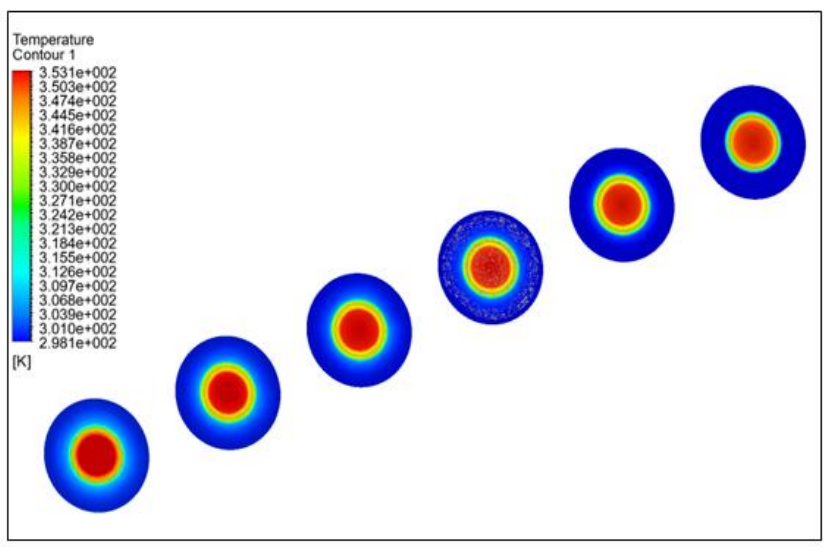

(a) 


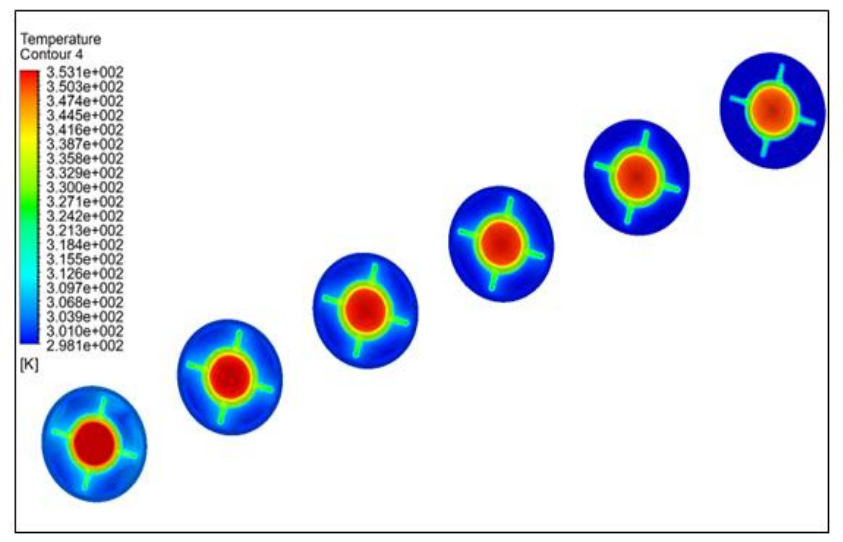

(b)

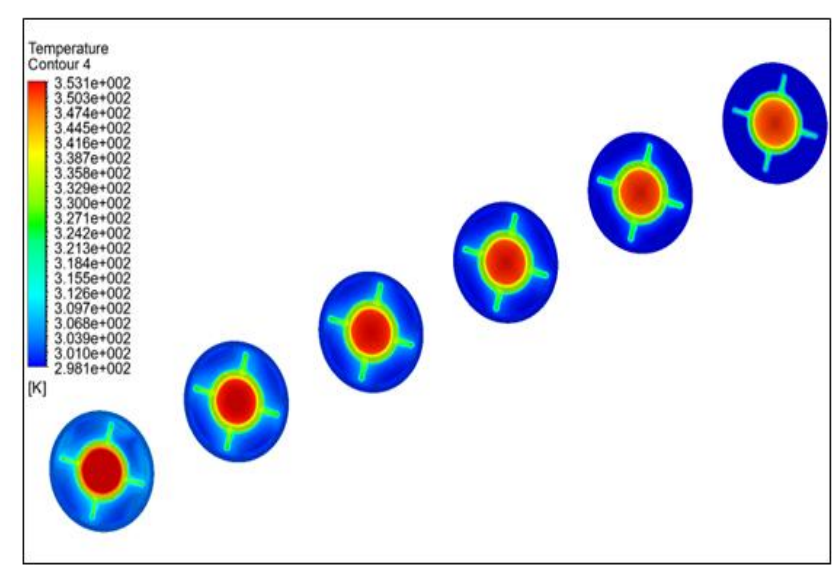

(c)

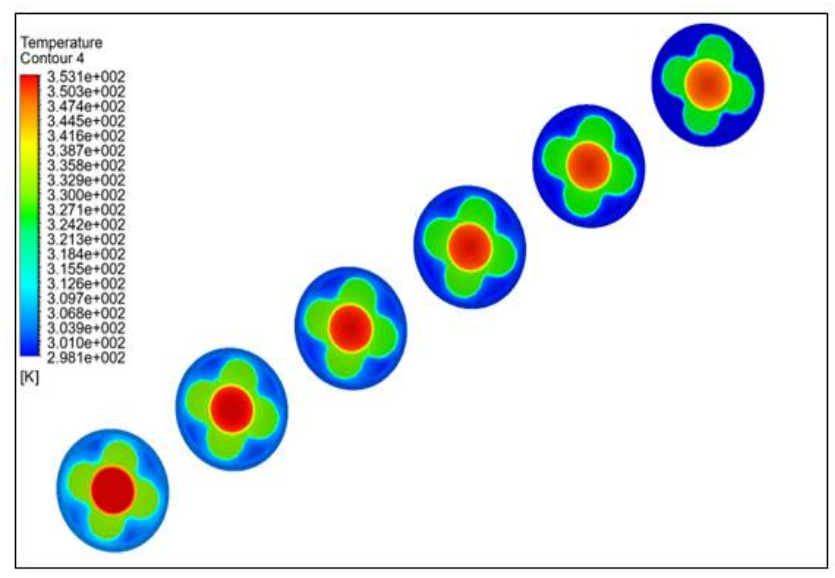

(d)

Fig.15. cross section temperature contour at $\mathrm{z}=0, \mathrm{z}=0.2, \mathrm{z}=0.4$, $\mathrm{z}=0.6, \quad \mathrm{z}=0.8 \mathrm{~m}$ and $\mathrm{z}=1 \mathrm{~m}$ (a) No. Fins (b) Rectangular (c) Triangular (d) Semi-circular finned annulus. at $\mathrm{m}_{\mathrm{h}}=0.3$ and $\mathrm{m}_{\mathrm{c}}=0.2 \mathrm{~kg} / \mathrm{s}$

\section{Conclusions}

In this paper, a numerical analysis was done to investigate the performance of FDPHE. Fins of different profiles of rectangular, triangular, and semi-circular were installed in the annulus side. From the results the following conclusions are obtained:

1. Regardless of their cross sections, the presence of fins enhances heat transfer rate.

2. The impact of installing fins on the thermal characteristics of the (DPHE) decrease with increasing mass flow rate.

3. Fins of Semi-circular cross section gave the better enhancement in thermal characteristics.

4. For a constant $\left(\mathrm{m}_{\mathrm{h}}\right)$ and varying values of $\left(\mathrm{m}_{\mathrm{c}}\right)$, semicircular finned pipe shows an improvement of $15 \%$ in cold water heat transfer rate over rectangular finned pipe and $16.8 \%$ over the triangular finned pipe. For a constant $\left(\mathrm{m}_{\mathrm{c}}\right)$ and varying the $\left(\mathrm{m}_{\mathrm{h}}\right)$ semi-circular finned pipe shows an improvement of $21.1 \%$ over rectangular finned pipe and $23.8 \%$ over the triangular finned pipe in cold water heat transfer rate

\section{Nomenclature}

$\mathrm{D}_{\mathrm{h}} \quad$ hydraulic diameter, $\mathrm{m}$

$\mathrm{A}_{\mathrm{c}} \quad$ cross sectional area, $\mathrm{m}^{2}$

$\mathrm{P}_{\mathrm{w}} \quad$ wetted perimeter, $\mathrm{m}$

$\mathrm{A}_{\mathrm{s}} \quad$ surface area, $\mathrm{m}^{2}$

$\mathrm{C}_{\mathrm{p}} \quad$ specific heat, $\mathrm{J} / \mathrm{kg} \mathrm{K}$

$\mathrm{K}_{\mathrm{f}} \quad$ fluid thermal conductivity, $\mathrm{W} / \mathrm{m} \mathrm{K}$

$\mathrm{T}_{\mathrm{s}} \quad$ surface temperature, $\mathrm{k}$

$\mathrm{T}_{\mathrm{m}} \quad$ mean temperature, $\mathrm{k}$

Q heat transfer rate, $\mathrm{W}$

$\mathrm{Nu} \quad$ nusselt number

$t_{f} \quad$ thickness of fin, $m$

$\mathrm{H}_{\mathrm{f}} \quad$ Fin height, $\mathrm{m}$

$\mathrm{L}_{\mathrm{f}} \quad$ Fin length, $\mathrm{m}$

$\mathrm{r} \quad$ Radius of semi-circular fin , $m$

$\mathrm{N}_{\mathrm{f}} \quad$ Fins number

$\mathrm{A}_{\mathrm{f}} \quad$ Fin surface area, $\mathrm{m}^{2}$

$\mathrm{A}_{\mathrm{uf}} \quad$ unfiinned part surface area , $\mathrm{m}^{2}$

\section{Greek symbols}

$\begin{array}{ll}\rho & \text { density, } \mathrm{kg} / \mathrm{m}^{3} \\ \mu & \text { dynamic viscosity, } \mathrm{kg} / \mathrm{m} \mathrm{s}\end{array}$

\section{Abbreviation}

DPHE double pipe heat exchanger

FDPHE finned double pipe heat exchanger 


\section{References}

[1] Shiva Kumar, k. Vasudev Karanth, Krishna Murthy, "Numerical study of heat transfer in a finned double pipe heat exchanger", World Journal of Modeling and Simulation, Vol. 11, No. 1, pp. 43-54, 2015.

[2] Z. Iqbal, K. S Syed, M. Ishaq, "Optimal convective heat transfer in double pipe with parabolic fins", International Journal of Heat and Mass Transfer, 54 (2011) 5415-5426.

[3] Nakul Sreedhar and George Varghese, "Analysis of longitudinal fin patterns in a concentric double tube heat exchanger using LMTD and CFD techniques", International Journal of Applied Engineering Research, Vol. 12, No. 17, pp. 6471-6479, 2017.

[4] N. Sreenivasalu Reddy and K. Rajagopal, "Numerical investigation of heat transfer enhancement and pressure drop of a double tube heat exchanger with rectangular fins in the annulus side", International Journal of Dynamics of Fluids, Vol. 13, No. 2, pp. 295-308, 2017.

[5] S. A. Nada and M. A. Said, "Effects of fins geometries, arrangements, dimensions and numbers on natural convection heat transfer characteristics in finned-horizontal annulus", International Journal of Thermal Sciences, 137 (2019) 121-137.

[6] Mathanraj V, Velaga Leela Krishna, Jampana Lakshmi Venkanna Babu, S. Arul Kumar, "Experimental investigation on heat transfer in double pipe heat exchanger employing triangular fins", IOP Conf. Series: Materials Science and Engineering, Vol. 402, No. 1, 2018.

[7] Davood Majidi, Hashem Alighardashi, Fatola Farhadi, " Experimental studies of heat transfer of air in a double-pipe helical heat exchanger", Applied Thermal Engineering, 133 (2018) 276282.

[8] S. Ramu, Tariku Achamyeleh, R. Srinivasan, KrishnaKumar K, " Analysis of heat generation in double pipe heat exchanger:An experimental evaluation and comparison of the heat transfer rate in the surface contact of the elliptical fin", International Research Journal of Engineering and Technology, Vol. 04, e-ISSN: 2395 0056, p-ISSN: 2395-0072, 2017.

[9] Vinous M. Hameed and Bashar Muslem Essa, "Experimental and numerical investigation to evaluate the performance of triangular finned tube heat exchanger", International Research Journal of Energy and Environment, Vol. 6, pp. 553-566, 2015.

[10] Abdulhassan A. Karamallah and Hisham A. Hoshi, "The effect of pitch and fins on enhancement of heat transfer in double pipe helical heat exchanger", International Journal of Scientific and Engineering Research, Vol. 6, Issue 10, ISSN 2229-5518, 2015.

[11] Lin Liu, Yuezhong Fan, Xiang Ling, Hao Peng, " Flow and heat transfer characteristics of finned tube with internal and external fins in air cooler for waste heat recovery of gas-fired boiler system", Chemical Engineering and Processing, 74 (2013) 142-152.

[12] MATT CABLE, "An Evaluation of Turbulence Models for the Numerical Study of Forced and Natural Convective Flow in Atria" MS. C. thesis, Queen's University, 2009.

[13] Marwa A. M. Ali, Wael M. El-Maghlany, Yehia A. Eldrainy, Abdelhamid Attia, "Heat transfer enhancement of double pipe heat exchanger using rotating of variable eccentricity inner pipe", Alexandria Engineering Journal, 57 (2018) 3709-3725.

[14] M. A. Yassin, H. M. Abd El-Hameed, M. H. Shedid, Abdel Hamid B.Helali, "Heat Transfer Enhancement through Annular Flow using Rotating Finned Pipe", Aerospace Science and Aviation Technology, ASAT-17-151-TH, 2017.

[15] Xiaoling Cao, Yanping Yuan, Bo Xiang, Liangliang Sun, Zhang Xingxing, "Numerical investigation on optimal number of longitudinal fins in horizontal annular phase change unit at different wall temperatures", Energy and Buildings, 158 (2018) 384-392.

[16] Anas El Maakoul, Azzeddine Laknizi, Said Saadeddine, Abdellatif Ben Abdellah, Mohamed Meziane, Mustapha El Metoui, "Numerical design and investigation of heat transfer enhancement and performance for an annulus with continuous helical baffles in a double-pipe heat exchanger", Energy Conversion and Management, 133 (2017) 76-86.

[17] Yunus A. Cengal, "Heat transfer", A Practical Approach, Second edition, McGraw-Hill Series in Mechanical engineering, 2010 . 